\title{
Effect of Ground Tire Rubber on Mechanical Properties of Low Density Polyethylene
}

\author{
Raza Muhammad Khan ${ }^{1}$, Asim Mushtaq ${ }^{1, *}$ and Zaeem Uddin $\mathrm{Ali}^{2}$ \\ ${ }^{1}$ Polymer and Petrochemical Engineering Department, NED University of Engineering \& Technology, Karachi, \\ Sindh, Pakistan \\ ${ }^{2}$ Chemical Engineering Department, NED University of Engineering \& Technology, Karachi, Sindh, Pakistan
}

\begin{abstract}
This research explores the effect of ground tire rubber (GTR) on the mechanical properties of LDPE. This thermoplastic-elastomer blend sets the composition of ground tire rubber and low-density polyethylene (LDPE/GTR). The blend was prepared in different proportions and was processed in a compression molding machine. The optimum operating conditions of the blend set to be $220^{\circ} \mathrm{C}$ temperature and pressure varied from $150-200$ bars. Different parts per hundred rubber (phr) samples were obtained under these conditions, including $1 \mathrm{phr}, 2 \mathrm{phr}, 3 \mathrm{phr}, 4 \mathrm{phr}$, and $5 \mathrm{phr}$. After that, the mechanical properties of the blend were examined concerning various compositions. Different testing methods were used to determine the mechanical properties of the thermoplastic-elastomer blend, which include tensile strength, flexural strength, and Izod impact. The results obtained from these tests show that tensile strength and modulus decreases by increasing the rubber content. However, impact strength and percentage elongation increase by increasing the rubber content. This enhancement in impact and percentage elongation may be suitable for the applications in gymnasium mat and automobile industry.
\end{abstract}

Keywords: Ground tire rubber, Izod strength testing, Low-density polyethylene, Thermoplastic elastomer, Percentage elongation.

\section{INTRODUCTION}

As the necessity of population increases, the manufacturing level additionally increases, which means the use of plastic is also rapidly increasing. It is employed for numerous purposes. In the same way, over the past several years, the uses of vehicles have increased tremendously, largely due to transportation which raises tire production. This worldwide scrap tire occupies huge amounts of landfill area globally. In Colorado, for illustration, there was a scrap tire site with 60 million tires weight approximately 550,000 tons of scrap thrown away on the land. Furthermore, more than two-thirds of the billions of tires used worldwide every year are discarded in the permitted or unauthorized waste areas [1, 2].

Waste tires stacked up like that attract diseasecarrying rodents, make the land useless, and release harmful substances to the atmosphere as they decay slowly. Waste tire scraps usually catch fire because of their size and the combustibility of tire materials. Sometimes waste tire fires could last up to several months; as millions of tires piled together. There must be a proper way to get rid of these millions of waste tires and develop a good technique to overcome this global issue $[3,4]$.

"Address correspondence to this author at the Polymer and Petrochemical Engineering Department, NED University of Engineering \& Technology, Karachi, Sindh, Pakistan; Tel: +92-99261261 Ext: 2419;

E-mail: engrasimmushtaq@yahoo.com

E-ISSN: $2410-1869 / 21$
The polymer waste represents a considerable portion of all waste materials. With the quick improvement of the vehicle business, waste tires contribute to the expanded polymer waste volume. A polymer mix like elastic thermoplastic mixes, when elastic rich, creates delicate thermoplastic elastomers, while plastic-rich mixes produce elastic hardened thermoplastic. Rubber hardened thermoplastics that display adaptable and high-sway properties will be utilized as economical alternatives to standard plastic materials.

The mechanical behavior of RR/SBR (reclaimed rubber/ styrene-butadiene rubber) and RR/NBR (reclaimed rubber/ nitrile butadiene rubber) blends studied reveal that arise within the strength, tear strength, elongation at break occurs with a decrease within the resilience. In the past few years, the concept to include the end of life tires into the low-density polyethylene has been proposed to overcome environmental pollution and other economic factors. The dynamic, static properties and morphology of the GTR/LDPE blend are studied [1, 4]. The reusing of end-of-life tires has become another solution for the energy recovery process utilized in Poland. The quantity of tires, which pollute the environment per one year, has increased by 200,000 tons p.a. in Poland $[5,6]$.

The influence of polarity of elastomer on the blend of HDPE/GTR was also explained $[5,6]$. Two 
copolymers, namely polar ethylene-(vinyl acetate) and nonpolar ethylene-octene copolymer, are tested. The result shows that the nonpolar ethylene-octene copolymer has greater mechanical properties than the polar one simply because of higher homogeneity. The compatibilization of various blends of GTR-PP/PE grafted via maleic anhydride with compatibilizing agents like butadiene-styrene or styrene-ethylene copolymer grafted via maleic anhydride were studied $[7,8]$. The results of the elastomeric material and dynamic vulcanization on the properties of the LDPE/GTR blend were examined. Effects of EPDM, $S B R$, and NR on the blend of LDPE/GTR were explained. The most effective was the one by the EPDM on the GTR/LDPE blend as described within the data published concluding that the dynamic vulcanization ends up in a positive result as increased within the elongation at break. It had been observed that the decrease in the lastingness of ethylene-vinyl acetate $23 \mathrm{MPa}$ on the introduction was $10 \%$ by weight GTR and $12.7 \mathrm{MPa}$ having particle size but $200 \mu \mathrm{m}$. Using the particle size $200-500 \mu \mathrm{m}$ or quite $500 \mu \mathrm{m}$, even lower values $10.4 \mathrm{MPa}$ and $84 \mathrm{MPa}$ respectively $[7,8]$.

In general, when the quantity of GTR is increased within the polymer composition, its mechanical properties decrease. Better substrates are introduced to extend the interference between the polymer and GTR to induce better mechanical properties. In one of the articles, it was examined that the compatibility of the thermoplastic/GTR using peroxide does not create a material that has thermoplastic elastomer properties [9]. However, the fresh elastomers are required within the blend of GTR/thermoplastic to accomplish the properties as by thermoplastics elastomer. Natural rubber rather than GTR was partially used with active filler within the variety of carbon. The application of GTR within $40 \%$ weight has increased the strength and hardness, and elongation at break decreased. It was seen that reclaimed elastic (RR) upgraded the effect strength of polypropylene (PP). When the RR is blended in with thermoplastics, it's relied upon to pass on the ascent to thermoplastic elastomers (all the more explicitly TPEs), and comparable examinations on piece elastic powder/LLDPE mixes are accounted for before. Thermoplastic elastomers got from WPE and RR, and their composites with new and Si-69 treated FA are read for their mechanical, dynamic mechanical properties. As morphological attributes these composites are utilized for making esteem added items like vibration dampers in industry, guards, light posts, floor tiles, and afterward on $[9,10]$.

In 2017 Lukasz Piszczyk et al. researched the likelihood of using polyurethane (PU) with GTR to supply compression-absorbing buoys and floating trays. Also stated is that incorporating GTR into the polyurethane increases the static mechanical properties and thermal stability. They studied the acoustic absorption of the blend of PU/GTR, which significantly increases the insulation properties of the blended foam [11].

The properties of elastic thermoplastic mixes are accounted for the sort of elastic/thermoplastic utilized, the synthesis, and bond between the stages by $R$. Scaffaro et al. [10]. Further, the grip between the materials relies upon the dissolving thickness of the lattice stage, the structure and size of the scattered particles, and in this way, the handling conditions. Moreover, mix properties additionally fluctuate with the molding methods acquainted with test examples [10].

In 2020 Marín-Genescà et al. reported that due to lack of adhesive between two phases, the blend's mechanical characteristics are weakening. It is because of GTR's large particle size, crosslinking and surface properties, which resist the molecular entanglement with polymers. Numerous effort has been made to make them homogeneous and to produce a composition with better properties $[6,7]$.

In 2021 Ali Fazil and Denis Rodrigue; reported that larger GTR particles increase the possibilities of larger voids, and tiny particles of GTR increase small cracks. It introduced the $20 \%$ by weight GTR $(200 \mu \mathrm{m})$ have decreased the enduringness by $25 \%$ (from $24 \%$ to $18 \%$ ). But on acid treatment (sulfonitric), the durability decreased by $13 \%$. The acid treatment increases the surface roughness by which the interaction of GTR with the matrix phase increases [12].

Regarding the environmental issues of ground tire rubber, when the tires are wasted, the chemicals and heavy metals are leached into the environment. These chemicals are carcinogenic and mutagenic, which cause cancer and gene mutations. The leaching of ground tires also affects the soil around the old tires; if the tires are moved from that place, the soil is still a toxin. So the toxins in the soil are transferred to the groundwater, and the water becomes harmful for living things when they come in contact with water. The hollow portion of the tires will contain rainwater and if 
the tires are left open to the atmosphere and the tires are undisturbed for a long period. It will create a breeding ground for mosquitoes. There is also a problem with the combustibility of tires. If the tires are burned, the chemicals are released to the surrounding, become harmful to human health. Also, the landfills problem is associated with the ground tires' rubber $[12,13]$.

The scope of research is to utilize the grounded tires in low-density polyethylene (LDPE) to produce LDPE/GTR blend. And secondly, to increase the impact strength of the LDPE by incorporating ground tire rubber (GTR) powder in it. The main objective of the research is to explore the effect of GTR on the mechanical properties of LDPE. LDPE is not a particularly strong polymer in comparison to others; it is primarily used for packaging. So using GTR as a filler in LDPE to observe its mechanical properties is aimed. As GTR has outstanding impact strength, and it's also an elastomer, when the composition of LDPE/GTR is set, we propose that it will probably improve its impact strength as well as percentage elongation.

\section{METHODOLOGY}

\section{Raw Materials}

The raw materials which are used are low-density polyethylene (LDPE), ethylene propylene diene monomer (EPDM), natural rubber (NR), styrenebutadiene rubber (SBR). Polyethylene is made by an additional polymerization reaction of ethylene monomers, as shown in Figure 1. The functional group of polyethylene (PE) is hydrogen. PE contains only carbon and hydrogen, generally high molecular weight, so it is pretty unaffected to most solvents. PE belongs to the polyolefin family of polymers and is categorized by its density and branching $[12,13]$.

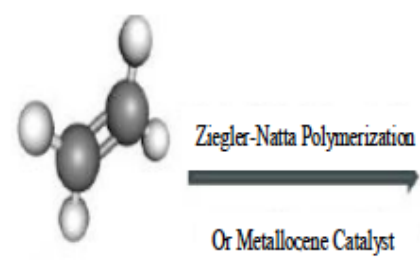

Monomer of PE

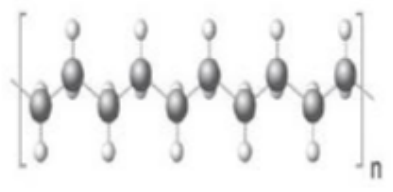

Structure of Polyethylene $\left(\mathrm{C}_{2} \mathrm{H}_{4}\right)_{n}$
Figure 1: Polymerization reaction of polyethylene.

High-density polyethylene (HDPE), low-density polyethylene (LDPE), and linear low-density polyethylene (LLDPE), the main focus is on LDPE. It is formed when high pressure and high temperature via free radical polymerization reaction takes place. It is a semi-rigid and translucent polymer as compared to HDPE. It has a higher degree of long and short sidechain branching. The density is low because that it rises the construction of many relatively long branches and avoid the molecules from packing close together to form crystal structures. It has low crystallinity (below $40 \%$ ). The LDPE consists of 4000 to 40000 carbon atoms, with many small branches. A highly amorphous nature structure affects the physical properties of LDPE. The melting temperature ranges from $105^{\circ} \mathrm{C}$ to $115^{\circ} \mathrm{C}$, and density ranges from $0.91-0.94 \mathrm{~g} / \mathrm{cm}^{3}$. Good chemical resistance to a dilute alkali, acids, and alcohols and limited resistance to hydrocarbons, aliphatic, oxidizing agent. Low water absorption (\% by wt. <0.01), clear in thin-film form, electrical insulating properties are excellent, good processability, and low cost. The disadvantages of LDPE are; low tensile strength, low stiffness, poor ultraviolet resistance, high flammable and vulnerability to stress cracking [11, 14$16]$.

\section{EPDM}

Ethylene propylene diene monomer (EPDM) comes from chemicals like monomers, which are mixed in different proportions to get it. It includes ethylene, propylene, and diene. Commonly $45 \%$ to $75 \%$ ethylene content is present. While diene monomers are only a minor component of EPDM, they offer the crosslinking that provides remarkable resilience, flexibility, and durability. EPDM's exceptional material characteristics are due to its molecular mesh structure, making it unique in terms of elasticity and aging resistance. EPDM rubber is a synthetic rubber material. Because it is highly flexible and durable, it has a broad range of uses, containing automobiles (used for door/window seals and cooling system hoses), non-slip coatings for decks and playgrounds, cold-rooms, and many more. The significant advantages of EPDM are; it has excellent weather resistance. It has the most waterproof rubber available; it can withstand abrasion, UV radiation, ozone, age, and weather. EPDM is also resistant to steam. It was operating at temperatures as high as 392 degrees Fahrenheit (200 degrees Celsius) without air and chemicals, including polar fluids. Its susceptibility to solvents, hydrocarbon oils, and certain lubricants, all of which can cause damage. Furthermore, unlike silicone, it is not flame resistant and is not suggested for food applications [14, 17]. 


\section{Natural Rubber}

It is natural rubber obtained from the latex of rubber trees. It can often be called cis-1,4 poly (isoprene). By cutting the bark to reach the latex vessels, it is collected in a cup installed on each tree. Rubber provides about $30-40 \%$ of the weight of this latex liquid. The assemblage of the latex sap, the natural rubber, is prepared to make it useable. At first, acid was added to the latex, making the sap solidify like jelly. The subsequent latex jelly was leveled, wrapped into elastic sheets, and hung to dry. Normal elastic consolidates solid malleable and tears strength with extraordinary exhaustion obstruction. It has extraordinary green strength and tack, implying it can append to itself and different materials, making it simpler to develop. One of its weaknesses is unassuming protection from natural corruption brought about by warmth, light, and ozone. Normal elastic bonds well to metal-plated steel wire, making it ideal for elastic tires. Lower hysteresis brings about diminished heat generation, preserving new tire service integrity, and broadening retread capacity. Natural rubber offers low moving opposition and further develops mileage. It is amazingly impervious to cutting, chipping, and tearing $[18,19]$.

\section{Styrene-Butadiene Rubber}

SBR is created by combining petroleum and natural gas. It is a synthetic rubber composed of styrene $25 \%$ and butadiene $75 \%$ monomers; it is sometimes used to replace natural rubber. Either emulsion polymerization or free-radical polymerization can be used to generate it. The most common general-purpose synthetic rubber is styrene-butadiene rubber (SBR). It may be utilized in applications comparable to NR / IR elastomers, except for strong dynamic applications due to the poorer fatigue resistance. Drive couplings, haul-off pads, conveyor belts, shoe bottoms and heels, adhesives, roll covers, and automobile tires are examples of typical uses (but not truck tires) and a variety of additional molded rubber products. For static sealing, the normal operating temperature range is $-25^{\circ} \mathrm{C}$ to $+100^{\circ} \mathrm{C}$. It has better abrasive resistance, heat resistance; it is better than natural rubber, has excellent corrosion resistance, low temperature flexibility, and tensile strength $[20,21]$.

\section{Process Equipment}

A grinding machine is one of the power tools commonly used for grinding and cutting the material. The grinding machine had different types of blades for different purposes. In this process, the angle grinder tool using. The abrasive disc is placed in a grinder which grinds the rubber in the form of uniform powder. The speed of the grinder plays an important role in the grinding of rubber. To ensure the speed of the grinder, and must be set according to the requirement. Ensure that there would be no crack on the disc while using the grinding machine.

Compression molding is a process in which a material acquires a restricted shape (according to the mold) by applying temperature and pressure. A compression molding machine is also called a laboratory hot press. This process consists of five major steps; set the optimal temperature according to the material requirements. I was preheating the mold and filling the material. Applied pressure according to the required conditions. The curing of the material.

\section{Preparation of Sample}

The experimental samples were being prepared by grinding the tire surface into powder form with the help of a grinding machine and filer. It incorporates lowdensity polyethylene (LDPE), which is also in powdered form. Samples were prepared by setting the composition of LDPE/GTR in phr form $1 \mathrm{phr}-5 \mathrm{phr}$ and prepared 15 samples of each composition of LDPE/GTR. Initially observed the formation of the sample by varying temperature and finally got the optimal temperature $220^{\circ} \mathrm{C}$. The powder form of LDPE/GTR was placed between hot plates of the compression molding machine at a constant temperature of $220^{\circ} \mathrm{C}$ and varying pressure (150-200) bar. Dumbbell shape samples were made to examine the mechanical properties of LDPE/GTR at different phr. The composition of LDPE/GTR was named as pure LDPE, $1 \mathrm{phr}$, 2phr, $3 \mathrm{phr}, 4 \mathrm{phr}$, and $5 \mathrm{phr}$, where phr refers to gram of GTR with 30 gram of LDPE. The samples were prepared at $0 \mathrm{~g}, 0.3 \mathrm{~g}, 0.6 \mathrm{~g}, 0.9 \mathrm{~g}, 1.2 \mathrm{~g}$, and $1.5 \mathrm{~g}$ of GTR. The samples were prepared as shown in Table 1.

Table 1: LDPE/GTR Samples Composition

\begin{tabular}{|c|c|c|c|}
\hline Samples & LDPE (g) & GTR $(\mathbf{g})$ & $\begin{array}{c}\text { Number of } \\
\text { Samples }\end{array}$ \\
\hline \hline Pure LDPE & 30 & 0 & 15 \\
\hline $1 \mathrm{phr}$ & 30 & 0.3 & 15 \\
\hline $2 \mathrm{phr}$ & 30 & 0.6 & 15 \\
\hline $3 \mathrm{phr}$ & 30 & 0.9 & 15 \\
\hline $4 \mathrm{phr}$ & 30 & 1.2 & 15 \\
\hline $5 \mathrm{phr}$ & 30 & 1.5 & 15 \\
\hline
\end{tabular}


The LDPE and GTR, both in powder form, were first weighed with the help of weight balance. Then mixed them and made a composition of LDPE/GTR according to the required phr. Set the machine at an optimal temperature of $220^{\circ} \mathrm{C}$. Firstly, preheat the mold, and after that filled the mold with the material. Then place the mold between two heat plates at a temperature of $220^{\circ} \mathrm{C}$ and different pressure (150-200) bar. Under the set, the condition material is melted and takes the shape of the mold. Mold is heated continuously for 3 min to give the samples a proper shape. After that, mold was taken out and continued to cool down for 10 minutes at room temperature. In the end, the dumbbell shape part is separated from the mold. Repeat the process until you prepare 15 samples of each phr.

\section{Sample Testing}

Different samples were tested at different phr. The basic objective of sample testing is to explore the mechanical properties of the low density of polyethylene with ground tire rubber. Tensile strength, flexural strength, and impact strength testing are done on prepared samples.

\section{Izod Impact Testing}

Izod impact testing can measure the impact energy that is the toughness of the sample. The hammer is raised at a specific height and then released it which hits a sample and absorbs the energy in it-using the US-based company manufacture of Ray-Ran testing equipment. The samples were prepared according to ASTM D256. The result from these tests mainly depends upon the materials. The velocity was set to $3.46 \mathrm{~m} / \mathrm{s}$, and the standard weight of the hammer was $0.905 \mathrm{~kg}$. The mean thickness of the samples was $3.3 \mathrm{~mm}$, and their mean width was $12.7 \mathrm{~mm}$.

\section{Flexural Strength Testing}

Flexural strength is also called bending strength. The flexural test can be performed on a Universal Testing Machine with samples standard according to ASTM D790. The core purpose of the flexural test was to find out the behavior of the sample when stress is located when the load is applied. In this testing, the sample is placed horizontally between the two fixed jaws while a movable jaw applies a force from the top until a sample bends. This test measures the maximum bending stress that the test sample can maintain before it fails. The speed of the machine was set at $50 \mathrm{~mm} / \mathrm{min}$, and also the span length of the specimen was $50 \mathrm{~mm}$. The mean thickness of the sample was $3.3 \mathrm{~mm}$, and their mean width was $12.2 \mathrm{~mm}$.

\section{Tensile Testing}

The tensile force is applied to a sample and measures the response of the sample. It defines how strong a material is and how much it can be stretchedusing Universal Testing Machine (UTM), which German company Zwick/Rowell manufactured. The samples were prepared according to ASTM D638. UTM was used for testing the sample by applying tensile stress. The speed of the machine was set at $50 \mathrm{~mm} / \mathrm{min}$, and also the span length of the specimen was $50 \mathrm{~mm}$. The mean thickness of the samples was $3.3 \mathrm{~mm}$, and their width was $12.38 \mathrm{~mm}$.

\section{RESULTS AND DISCUSSION}

Five samples of each composition of LDPE/GTR, which was in phr, have been tested, and the results and their mean width, thickness and IZOD, flexural strength, tensile strength, modulus, and percentage elongation have been recorded. Similar results were achieved when testing 5 samples of each composition of LDPE/GTR.

\section{IZOD Test}

The impact energy will increase as the GTR content in the composition of the LDPE/GTR blend increases, as shown in Figure 2. It is found that as the rubber content in a composition LDPE/GTR increases, the impact strength of the sample gradually increases because the rubber can absorb the energy. After all, it is an elastomer, and they are cross-linked, and also they are above glass transition temperature $T g$ at room temperature that is why they are flexible. The good impact strength was achieved because of the fracture toughness behavior of GTR [7, 12, 20, 21].

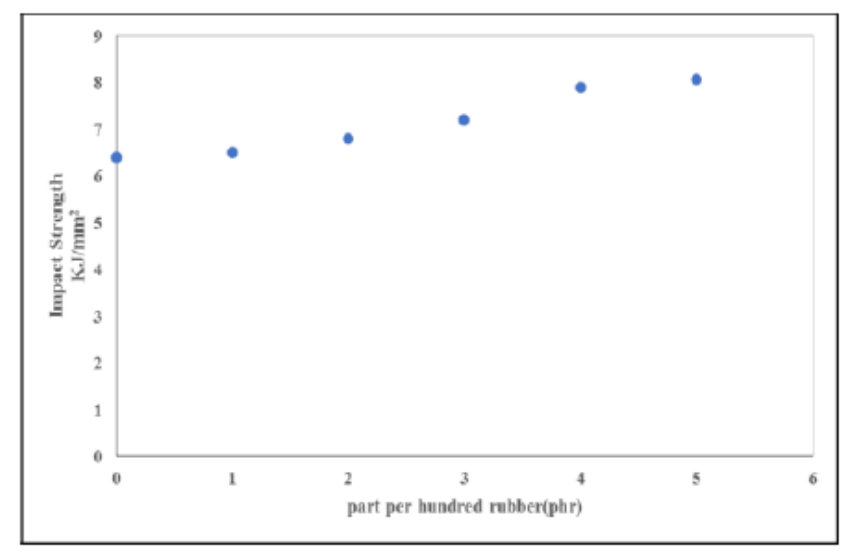

Figure 2: Effect of rubber content on the impact strength of LDPE/GTR blend. 


\section{Flexural Test}

From Figure 3, it is observed that as the rubber content in a composition LDPE/GTR increases, the flexural strength of the sample decreases. It may be due to the low stiffness of LDPE compared to other thermoplastic materials and maybe due to void or defect inside the blend. Also, rubber can resist when the load is applied. Further, adding the rubber material to it will significantly affect its stiffness and reduce its flexural strength. The flexural strength at break cannot be calculated as the sample was not broken during applied load. So the flexural strength was calculated at $25 \%$ deformation. The blended material shows good flexibility by reducing the stiffness of the overall composition [11, 15, 16, 19, 22].

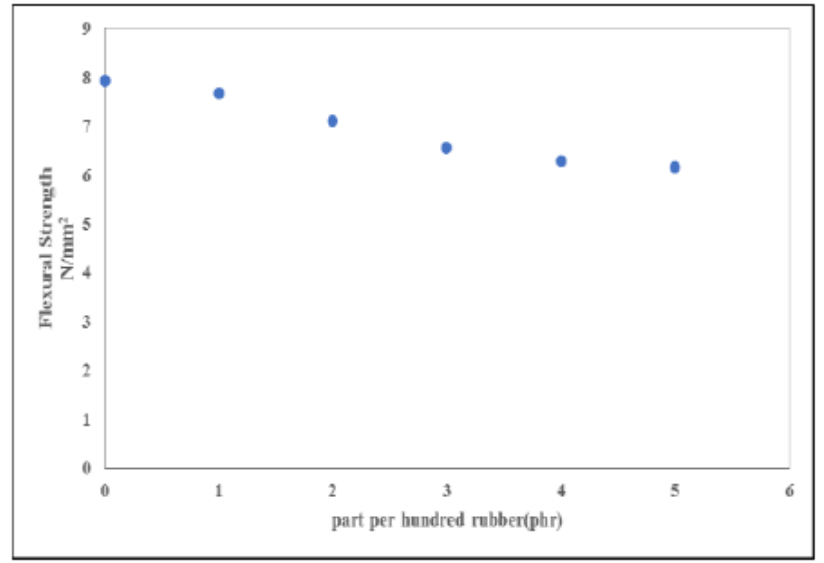

Figure 3: Effect of rubber content on the flexural strength of LDPE/GTR blends.

\section{Tensile Test}

From Figure 4, the effect of the rubber content on the modulus of LDPE/GTR blends is observed. The

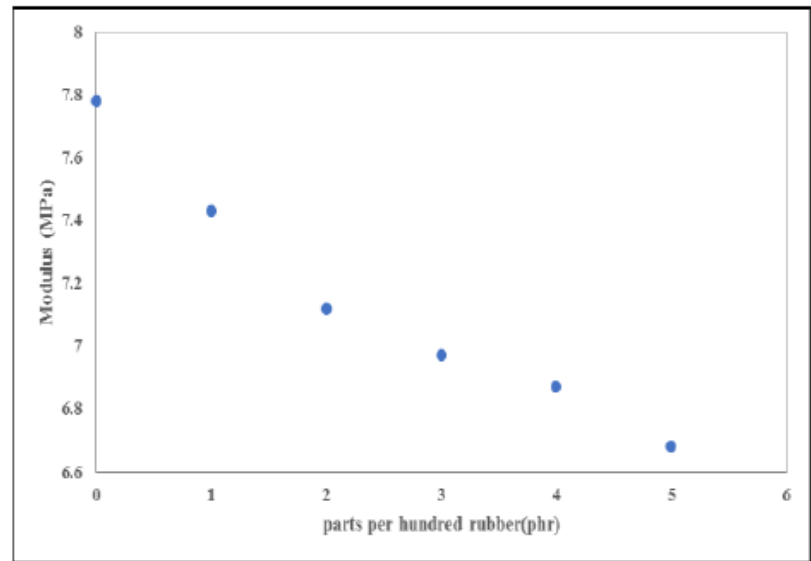

Figure 4: Effect of rubber content on the modulus of LDPE/GTR blends. elastic modulus decreases by increasing the rubber content in LDPE/GTR blend, due to poor compatibility between GTR and LDPE. The rubber molecules did not get sufficient freedom to entangle with LDPE molecules to form strong bonding between GTR/LDPE. The rubber has a low modulus compared to the thermoplastic material $[3,4,7,18]$.

In Figure 5, the trend shows that as the GTR content increases from pure LDPE to $5 \mathrm{phr}$, the tensile strength decreases from 111 to $79.21 \mathrm{~N} / \mathrm{mm}^{2}$. This decrease is not only due to weak affinity between blends, but also due to degradation of recycling GTR by exposure to the atmosphere or during their use while processing and grinding.

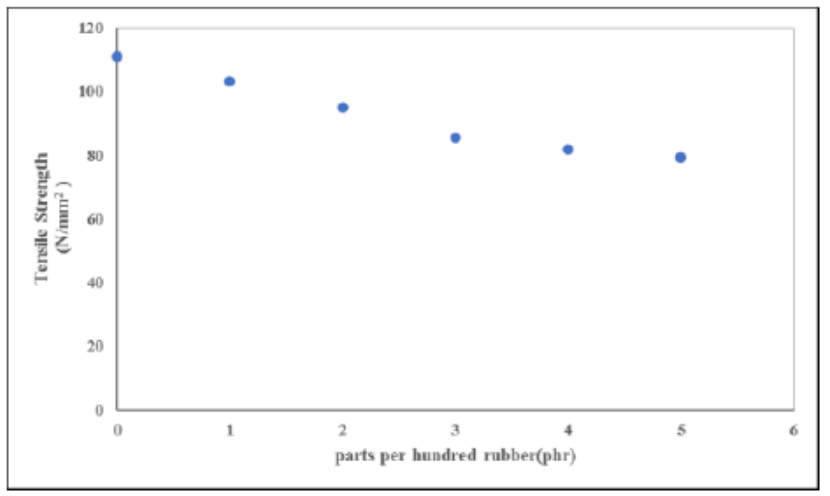

Figure 5: Effect of rubber content on the tensile strength of LDPE/GTR blends.

In Figure 6, it is observed that as the rubber content increase, the percentage elongation increases because of the slight increase in plastic deformation due to the presence of elastic phase, which persuading higher elasticity in the samples. According to the tensile results, it was observed that the rubber content is showing its effect by increasing elongations as we have

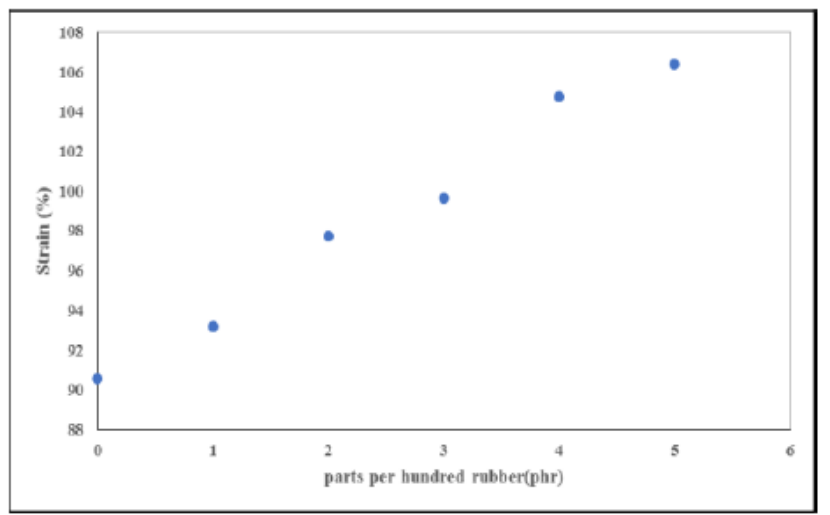

Figure 6: Effect of rubber content on the elongation of LDPE/GTR blends. 
more elastic properties in rubber and decreasing the modulus and tensile strength of the blend. The blend has good energy absorption capabilities with mechanical balance properties compared to pure rubber material $[9,11,16,17]$.

\section{CONCLUSION}

Thermoplastic-elastomer blend was prepared from ground tire rubber (GTR), and low-density polyethylene (LDPE) on a hot press compression molding machine, and its properties were examined in detail. It was noticed that percentage elongation and impact strength increases when the rubber content is increased in the blend as compared to virgin LDPE. The percentage elongation of pure LDPE is $90.56 \%$, and the percent elongation was increased in phr, and at $5 \mathrm{phr}$, it is found to be $106.39 \%$. Similarly, the flexural strength of pure LDPE is $7.93 \mathrm{~N} / \mathrm{mm}^{2}$, and its strength decreases in phr, and at $5 \mathrm{phr}$, it is found to be $6.146 \mathrm{~N} / \mathrm{mm}^{2}$. Similarly, the impact strength of pure LDPE is 6.4 $\mathrm{KJ} / \mathrm{mm}^{2}$, and its impact strength is increased in $\mathrm{phr}$, and at $5 \mathrm{phr}$, it is found to be $8.06 \mathrm{KJ} / \mathrm{mm}^{2}$. Furthermore, tensile strength, and modulus decreased with the incorporation of rubber content in the blend. The decrease in tensile and modulus was from 111 $\mathrm{N} / \mathrm{mm}^{2}$ to $79 \mathrm{~N} / \mathrm{mm}^{2}$, and $7.78 \mathrm{MPa}$ to $6.68 \mathrm{MPa}$, respectively, in a $5 \mathrm{phr}$ blend. Better mixing would be obtained while using an extruder which may give a good uniformity of the LDPE/GTR blend. Homogeneity of the GTR/LDPE blend can be observed by scanning electron microscopy. From previous studies [ref], it can also deduced that GTR can be incorporated with other polymer matrices for better enhancement in properties. The thermal properties of the GTR/LDPE blend can be analyzed.

\section{NOMENCLATURE}

$\begin{array}{ll}\text { SBR } & \text { Styrene-butadiene rubber } \\ \text { NBR } & \text { Nitrile butadiene rubber } \\ \text { FA } & \text { Fly ash } \\ \text { PE } & \text { Polyethylene } \\ \text { PP } & \text { Polypropylene } \\ \text { NR } & \text { Natural rubber } \\ \text { PU } & \text { Polyurethane } \\ \text { UV } & \text { Ultraviolet }\end{array}$
UTM Universal testing machine
PHR Parts per hundred rubber
GTR Ground tire rubber
LDPE Low-density polyethylene
HDPE High-density polyethylene
EPDM Ethylene propylene diene monomer
TPE Thermoplastic elastomers
RR Reclaimed rubber
LLDPE Linear low-density polyethylene
ASTM American standard testing material

\section{REFERENCES}

[1] Simon-Stoger L, Varga C. PE-contaminated industrial waste ground tire rubber: How to transform a handicapped resource to a valuable one. Waste Manag. 2021; 119: 111-21. https://doi.org/10.1016/j.wasman.2020.09.037

[2] Zedler L, Burger P, Wang S, Formela K. Ground Tire Rubber Modified by Ethylene-Vinyl Acetate Copolymer: Processing, Physico-Mechanical Properties, Volatile Organic Compounds Emission and Recycling Possibility. Materials. 2020; 13: 119.

https://doi.org/10.3390/ma13204669

[3] Formela K, Hejna A, Zedler $Ł$, Przybysz M, Ryl J, Saeb MR, et al. Structural, thermal and physico-mechanical properties of polyurethane/brewers' spent grain composite foams modified with ground tire rubber. Ind. Crops Prod. 2017; 108: 844-52.

https://doi.org/10.1016/j.indcrop.2017.07.047

[4] Nizamuddin S, Jamal M, Gravina R, Giustozzi F. Recycled plastic as bitumen modifier: The role of recycled linear lowdensity polyethylene in the modification of physical, chemical and rheological properties of bitumen. J. Cleaner Prod. 2020; 266: 1-12.

https://doi.org/10.1016/j.jclepro.2020.121988

] Duarte GM, Faxina AL. High-temperature rheological properties of asphalt binders modified with recycled lowdensity polyethylene and crumb rubber. Constr. Build Mater. 2021; 298: 1-12.

https://doi.org/10.1016/j.conbuildmat.2021.123852

[6] Marín-Genescà M, García-Amorós J, Mujal-Rosas R, Vidal LM, Arroyo JB, Fajula XC. Ground Tire Rubber Recycling in Applications as Insulators in Polymeric Compounds, According to Spanish UNE Standards. Recycling. 2020; 5: 114.

https://doi.org/10.3390/recycling5030016

[7] Marin-Genesca M, Garcia-Amoros J, Mujal-Rosas R, Massagues L, Colom X. Study and Characterization of the Dielectric Behavior of Low Linear Density Polyethylene Composites Mixed with Ground Tire Rubber Particles. Polymers. 2020; 12: 1-19. https://doi.org/10.3390/polym12051075

[8] Soriano-Corral F, Hernández-Gámez JF, Durón-Sánchez LHI, Ramos de Valle LF, Lozano-Estrada M, Soto-Lara YA. Polymer Foams Based on Low Density Polyethylene/Ethylene Vinyl Acetate/Ground Tire Rubber (LDPE/EVA/GTR): Influence of the GTR Particle Size and 
Content on the Cellular Morphology and Density of the Final Foamed Compounds. Key Eng. Mater. 2018; 779: 64-70. https://doi.org/10.4028/www.scientific.net/KEM.779.64

[9] Mészáros L, Kara Y, Fekete T, Molnár K. Development of self-reinforced low-density polyethylene using $\mathrm{Y}$-irradiation crosslinked polyethylene fibres. Radiat. Phys. Chem. 2020; 170: $1-6$.

https://doi.org/10.1016/..radphyschem.2019.108655

[10] Scaffaro R, Maio A, Sutera F, Gulino EF, Morreale M. Degradation and Recycling of Films Based on Biodegradable Polymers: A Short Review. Polymers. 2019; 11: 1-20. https://doi.org/10.3390/polym11040651

[11] Rahmani M, Adamian A, Hosseini-Sianaki A. Effect of Waste Ground Rubber Tire Powder on Vibrational Damping Behavior and Static Mechanical Properties of Polypropylene Composite Plates: An Experimental Investigation. J. Mater. Eng. Perform. 2021; 30: 1-9. https://doi.org/10.1007/s11665-021-06073-9

[12] Fazli A, Rodrigue D. Effect of Ground Tire Rubber (GTR) Particle Size and Content on the Morphological and Mechanical Properties of Recycled High-Density Polyethylene (rHDPE)/GTR Blends. Recycling. 2021; 6: 1-20. https://doi.org/10.3390/recycling6030044

[13] Favakeh M, Bazgir S, Karbasi M. Dynamically vulcanized thermoplastic elastomer nanocomposites based on linear low-density polyethylene/styrene-butadiene rubber/nanoclay/bitumen: morphology and rheological behavior. Iran. Polym. J. 2020; 29: 209-17. https://doi.org/10.1007/s13726-020-00786-9

[14] Arsyad H, Arma LH, Syahid M, Khalid M. An experimental study of tensile properties and vibration absorption characteristic of ground tire rubber (GTR )/HDPE waste: Effect of temperature and heating time. IOP Conf. Ser: Mater. Sci. Eng. 2021; 1034: 1-10. https://doi.org/10.1088/1757-899X/1034/1/012159

[15] Moghaddamzadeh S, Rodrigue D. The effect of polyester recycled tire fibers mixed with ground tire rubber on polyethylene composites. Part II. Prog Rubber, Plast. Recycl. Technol. 2018; 34: 128-42.

https://doi.org/10.1177/1477760618798268

[16] Sampath WDM, Egodage SM, Edirisinghe DG. Effect of Peroxide Loading on Properties of Natural Rubber and Lowdensity Polyethylene Composites. J. Phys. Sci. 2019; 30: 4969.

https://doi.org/10.21315/jps2019.30.3.4

[17] Kiss L, Simon DÁ, Petrény R, Kocsis D, Bárány T, Mészáros L. Ground tire rubber filled low-density polyethylene: The effect of particle size. Adv. Ind. Eng. Polym. Res. 2021; 4: 116.

https://doi.org/10.1016/j.aiepr.2021.07.001

[18] Jiang $\mathrm{C}$, Zhang $\mathrm{Y}, \mathrm{Ma} \mathrm{L}$, Zhou L, He H. Tailoring the properties of ground tire rubber/high-density polyethylene blends by combining surface devulcanization and in-situ grafting technology. Mater. Chem. Phys. 2018; 220: 161-70. https://doi.org/10.1016/i.matchemphys.2018.08.040

[19] Zhang $X$, Feng $R$, Wang Z. Reusing ground tire rubber powder as thermoplastic elastomers with excellent superhydrophobicity and self-cleaning performance. Prog. Rubber, Plast. Recycl. Technol. 2021; 37: 1-17. https://doi.org/10.1177/14777606211019422

[20] Song P, Li S, Wang S. Interfacial interaction between degraded ground tire rubber and polyethylene. Polym. Degrad. Stab. 2017; 143: 85-94. https://doi.org/10.1016/j.polymdegradstab.2017.06.020

[21] Tian F, Chen L, Xu X. Dynamical mechanical properties of wood-high density polyethylene composites filled with recycled rubber. J. Bioresour. Bioprod. 2021; 6: 152-9. https://doi.org/10.1016/j.jobab.2021.02.007

[22] Hong SH, Hwang $\mathrm{SH}$. Construction and foamability of ligninreinforced low-density polyethylene biocomposites. Mater. Today Commun. 2021; 28: 1-9. https://doi.org/10.1016/j.mtcomm.2021.102696

(c) 2021 Khan et al.; Licensee Cosmos Scholars Publishing House.

This is an open access article licensed under the terms of the Creative Commons Attribution Non-Commercial License (http://creativecommons.org/licenses/by-nc/3.0/), which permits unrestricted, non-commercial use, distribution and reproduction in any medium, provided the work is properly cited. 